\title{
Policy Brief: Possible Changes to Health Coverage of Rural Children Should Concern Educators
}

\author{
Cathy Grace \\ University of Mississippi
}

In May, House Republicans passed a bill that would dismantle the Affordable Care Act, the current health care insurance plan provided to low income families. The non-Partisan Congressional Budget Office reviewed the legislation, and has determined that if some portion of the legislation is also passed by the Senate, it would leave 14 million more people uninsured next year than under current law - and 23 million more uninsured in 2026. In addition, some of the nation's sickest would pay much more for health care (Pear, 2017). In June, the Senate began releasing details of the Better Care Reconciliation Act.

As the fight rages on over whether to discontinue the Affordable Care Act and replace it, or to modify the ACA, as proposed by Democrats, some Republicans and numerous children's advocacy groups, it is important to understand the differences between the current legislation and the version currently being considered from a rural perspective. Given that Medicaid, the Children's Health Insurance Program, and Medicare are focal points in the health care debate and part of the Affordable Care Act's comprehensive design, definitions of the programs (see side bar) are important to adequately understand what is at the heart of the ideological conflict.

A study released in June 2017 by Georgetown University Health Policy Institute, Center for Children and Families and The North Carolina Rural Health Research Program indicates Medicaid covers a larger share of children and families in small towns and rural areas than in large metropolitan areas. In 2014-2015, Medicaid provided health coverage for 45 percent of children and 16 percent of adults in small towns and rural areas, compared to 38 percent and 15 percent, respectively, in metropolitan areas. Also mentioned in the report were that rural Americans have lower household incomes, lower rates of workforce participation, and higher rates of disability-all factors associated with Medicaid eligibility. In addition, the Affordable Care Act passed in 2010, led to more aggressive efforts to enroll children in Medicaid and the Children's Health Insurance Program (CHIP). In 2014-15 fourteen states registered more than half of children in the state through Medicaid or CHIP (Alker, Hoadley, Holmes \& Wagernman, 2017). The Georgetown study also examined Medicaid and CHIP state

\section{Federal Health Care Programs}

Medicaid provides health coverage to millions of Americans, including eligible low-income adults, children, pregnant women, elderly adults and people with disabilities. Medicaid is administered by states, according to federal requirements. Health coverage is provided to over 72.5 million Americans. Medicaid is the single largest source of health coverage in the United States. The program is funded jointly by states and the federal government

\section{Children's Health Insurance Program} (CHIP) provides health coverage to eligible children, through both Medicaid and separate CHIP programs. CHIP is administered by states, according to federal requirements. The program serves uninsured children up to age 19 in families with incomes too high to qualify them for Medicaid. States have broad discretion in setting their income eligibility standards, and eligibility varies across states. The program is funded jointly by states and the federal government

Medicare is the federal health insurance program for people age 65 or older, under 65 with certain disabilities, and any age with endstage renal disease (permanent kidney failure requiring dialysis or a kidney transplant)

Affordable Care Act passed in 2010 and sometimes referred to as "Obama Care" is the law which provides consumers with subsidies ("premium tax credits") that lower costs for households with incomes between $100 \%$ and $400 \%$ of the federal poverty level. It is managed at the state level and has different provisions based on choices determined by the state 
enrollments during two years and concluded that due to the large number of children in small towns and rural areas of the country participating, any decrease in funding for either program would put thousands of children back into the uninsured category and raise the risk of limited or no health services.

Educators in rural areas of America often become advocates for the education of children by advocating for related issues such as access to health care for all children regardless of family income or any pre-existing condition. With the health care debates, it appears this is one of those instances. Children are unable to learn if they are absent from school. When preventive care is unaffordable for many rural families, a routine cold can turn into bronchitis, pneumonia or the flu. The child is absent more days from school since he received no medical care at the onset which resulted in higher medical expenses for families often making minimum wage when emergency care is required.

In some cases, families are forced to choose paying for other basic needs such as rent, food and gas for transportation to work or medical or pharmaceutical bills. As a result, children often attend school with contagious diseases such as strep throat or flu and spread the disease to others resulting in numerous children becoming ill, missing school, and losing learning time.

Specific illnesses such as asthma, sickle cell anemia, juvenile diabetes are all potentially deadly to children without the appropriate medical care and medicine. Again, Medicaid or CHIP has served as a safety net for the children and families affected. Without a stable medical home, the risk of the child's poor attendance at school, quality of life, and failure to fully participate in the school experience can be emotionally devastating as well as academically challenging, not to mention potentially shortening the child's life. Who can better speak to the need for continued services than educators, medical professionals and parents?

Infants, toddlers and preschoolers are especially vulnerable to health issues. Without the medical guarantee offered through Medicaid or CHIP children in low income families are subject to developmental delays due to undiagnosed relatively minor illnesses such as an ear infection, which if left untreated may cause hearing loss or language delay ("Ear Infections with Fluid,” n.d.).

The health plans being debated in congress would impact rural America, perhaps more than any other segment in the country. There are many proposals being considered as to how government will fund and administer health care insurance for children. Each person in each community needs to get facts about the potential changes. Non-partisan resources for learning about health care proposals include the Medicaid Director or Insurance Commissioner in your state. AASA: The School Superintendents Association, has provided talking points that can support your advocacy:

http://www.aasa.org/policyblogs.aspx?id=41251\&blogid=84002. In addition, a review of various proposals is provided by the Kaiser Family Foundation at http://www.kff.org/healthreform/. These resources allow the novice reader to better understand the impact of potential changes in rural communities.

At the time this is being written, it is too soon for anyone to know what is going to absolutely happen, but it is not too soon for conversations with political leaders and advocacy for children's health. Children alone do not carry much weight with elected officials, but family members, teachers and community advocates do. There is power in numbers.

\section{References}

Alker, J., Hoadley, J, Holmes, M \& Wagernman, K. (2017). Medicaid in Small Towns and Rural America: A Lifeline for Children, Families and Communities. Washington, DC: Georgetown University Center for Children and Families and The North Carolina Rural Health Research Program.

The Henry J,Kaiser Family Foundation (2017) Compare Proposals to Replace the Affordable Care Act, (n.d.) Retrieved June 17, 2017, from http://www.kff.org/interactive/proposals-toreplace-the-affordable-careact/?gclid=CjwKEAjwppPKBRCGwrSpqK7Y5
jcSJACHYbWY0FmdClL9VSzuJpcMAEy6qV J4VLHtdVXhcutpA96vOxoCKZzw_wcB

Children's Health Insurance Program (CHIP). (n.d.). Retrieved June 11, 2017, from https://www.medicaid.gov/chip/chip-programinformation.html

Ear Infections with Fluid - HealthyChildren.org. (2015, Nov. 21). Retrieved June 11, 2017, from https://www.healthychildren.org/English/health -issues/conditions/ear-nose-throat/Pages/EarInfections-with-Fluid.aspx 
Medicaid. (n.d.). Retrieved June 11, 2017, from https://www.medicaid.gov/medicaid/index.html

Pear, R. (2017, May 24). G.O.P. Health Bill Would Leave 23 Million More Uninsured in a Decade, C.B.O. Says. Retrieved June 11, 2017, from https://www.nytimes.com/2017/05/24/us/politic s/cbo-congressional-budget-office-healthcare.html

Presidential Election Results. (n.d.). Retrieved June 10, 2017, from

http://www.cnn.com/election/results/president

\section{About the author:}

Dr. Grace is the co-director of the Graduate Center for the Study of Early Learning at the University of Mississippi. She has worked in early childhood education for over 40 years at the national, regional, state and local level. She grew up in Crittenden County Arkansas. 